\title{
Propiedades Fisicoquímicas, Funcionales y Microbiológicas de Lechuga (Lactuca sativa L.) adicionada con Ácidos Orgánicos
}

\author{
Daniel A. Rodríguez ${ }^{(1)}$, Rodrigo Ortega-Toro(2) y Yineth Piñeros-Castro(1) \\ (1) Facultad de Ingeniería, Dpto. de Ingeniería, Programa de Ingeniería de alimentos, Univ. de Bogotá Jorge \\ Tadeo Lozano, Carrera 4 \# 22-6, Bogotá D.C. Colombia, \\ (2) Facultad de Ingeniería, Dpto. de Ciencias de los Alimentos, Grupo IFCRA, Univ. de Cartagena, Carrera 6 \\ \# 36-100, Cartagena de Indias D.T. y C. Colombia (e-mail: yineth.pineros@utadeo.edu.co; \\ rortegap1@unicartagena.edu.co)
}

Recibido Nov. 17, 2017; Aceptado Ene. 22, 2018; Versión final Feb. 8, 2018, Publicado Ago. 2018

\begin{abstract}
Resumen
Este trabajo plantea la utilización de tratamientos con ácidos orgánicos (acético, cítrico y láctico) como alternativa para prevenir el deterioro de la lechuga (Lactuca sativa $L$.) variedad Batavia y extender su tiempo de vida útil. La lechuga es una hortaliza considerada como funcional dado a su poder antioxidante y contenido de compuestos fenólicos. Sin embargo, un inapropiado manejo durante la postcosecha puede no solamente afectar estas características, sino también producir pérdida de agua, contaminación microbiana y pardeamiento enzimático. Se realizó el seguimiento de sus características fisicoquímicas, funcionales y microbiológicas, bajo un esquema simulado de una cadena de comercialización en la Sabana de Bogotá (tiempo, temperatura y humedad relativa). Los resultados muestran diferencias estadísticamente significativas $(\alpha<0,05)$ para el índice de calidad y color (pardeamiento enzimático). Respecto a la población microbiana nativa, los ácidos estudiados promueven la disminución de la población de microorganismos hasta las 6 horas luego del tratamiento.
\end{abstract}

Palabras clave: lechuga; postcosecha; antioxidantes; microbiología; fenoles

\section{Physicochemical, Functional and Microbiological Properties of Lettuce (Lactuca sativa L.) Added with Organic Acids}

\begin{abstract}
This work proposes the use of treatments with organic acids (acetic, citric and lactic) as an alternative to prevent the deterioration of the lettuce (Lactuca sativa L,) Batavia variety and extends its shelf life. Lettuce is a vegetable considered as functional given its antioxidant power and content of phenolic compounds. However, inappropriate handling during post-harvesting can not only affect these characteristics but also produce water loss, microbial contamination and enzymatic browning. The physicochemical, functional and microbiological characteristics were monitored, under a simulated scheme of a marketing chain in the Sabana de Bogotá (time, temperature and relative humidity). The results show statistically significant differences $(\alpha<0.05)$ for the quality and color index (enzymatic browning). Regarding the native microbial population, the acids considered promote the decrease of the microorganism population until 6 hours after treatment.
\end{abstract}

Keywords: lettuce; postharvest; antioxidants; microbiology; phenols 


\section{INTRODUCCIÓN}

La tendencia mundial hacia el consumo de productos mínimamente procesados ha hecho que se adapten nuevas tecnologías para la conservación de los alimentos, como aquellas que previenen daños a las características del producto y reducen o eliminan la carga microbiana presente, dado que pueden representar un foco de microorganismos patógenos, responsables de brotes de gastroenteritis o listeriosis (CastañedaRuelas et al., 2014). En lechugas de cabeza o de hojas apretadas como la variedad batavia, se mantiene su calidad poscosecha por más tiempo al almacenarlas bajo condiciones óptimas (temperatura $0-1^{\circ} \mathrm{C}$ y $\mathrm{HR}>$ $95 \%$ ). Si las condiciones de almacenamiento se alteran durante la comercialización, se puede dar lugar al fenómeno de marchitamiento, conllevando a una reducción severa de la calidad (Ding et al., 2016).

En una cadena de comercialización ideal la temperatura del aire durante la distribución y almacenamiento debe ser inferior a $10^{\circ} \mathrm{C}$ (Tirpanalan et al., 2011), posteriormente la temperatura debe ser máximo de $5^{\circ} \mathrm{C}$. Se ha identificado que las fluctuaciones de temperatura durante la etapa de transporte y distribución $\left(T>5^{\circ} \mathrm{C}\right)$ es uno de los principales factores que incrementan el recuento bacteriano en la lechuga (McKellar, et al., 2012), situación que favorece el riesgo de originar brotes de enfermedades de origen alimentario a partir de estos productos. En general la vida útil de la lechuga fresca, se ve limitada por la presencia de microorganismos, reacciones de pardeamiento enzimático, pérdida de textura y aparición de olores no deseables (Gutiérrez et al., 2016).

Por otro lado, las alteraciones en las lechugas están asociados con una alta tasa de respiración y pérdida de agua lo que ocasiona no solamente pérdida de peso, sino también de daño en apariencia, textura y calidad nutricional (Blanch et al., 2017). En este contexto los tratamientos poscosecha son indispensables para prevenir el deterioro de las hortalizas, disminuir el porcentaje de pérdidas poscosecha y aumentar el tiempo de vida útil, a las condiciones de manejo usualmente utilizadas en las cadenas de comercialización en la Sabana de Bogotá.

El pardeamiento del tallo de la lechuga se debe a la activación de enzimas como la polifenoloxidasa (PPO) por parte del etileno que actúan cuando hay daños en los tejidos (Bohórquez et al., 2013), proceso que se activa durante el corte del tallo. El control del pardeamiento enzimático de las lechugas durante las etapas de la cosecha y la poscosecha es de importancia para minimizar la pérdida del producto, ya que conduce a pérdidas nutricionales, funcionales y cualidades organolépticas, tales como oscurecimiento, ablandamiento y pérdidas del sabor característico. Rivera et al., (2004) han reportado un buen control del pardeamiento enzimático en la lechuga con la aplicación de manera conjunta de los ácidos ascórbico, cítrico y oxálico. Sin embargo, la aplicación de ácidos orgánicos, puede afectar al producto en su apariencia, textura y color, por lo que se hace necesario el estudio previo de las mezclas a utilizar.

En cuanto al uso de los ácidos orgánicos para prevenir el desarrollo microbiano en alimentos, se ha comprobado el poder desinfectante de los ácidos propiónico, acético, láctico, málico y cítrico, los cuales resultaron ser efectivos en el control de E. coli O157:H7, S. typhimurium y L. monocytogenes (Park et al., 2011). En este trabajo se evaluó el efecto del tratamiento con ácidos orgánicos (láctico, acético y cítrico) mediante la simulación de una cadena de comercialización de lechuga, sobre algunos parámetros de calidad como acidez titulable, sólidos solubles, color, contenido de compuestos fenólicos, actividad antioxidante y población microbiana nativa. Previamente al desarrollo de este trabajo se estudió el efecto de los ácidos orgánicos láctico, acético, cítrico sobre las poblaciones de Listeria monocytogenes ATCC 19114, Salmonella enteriditis ATCC 13076 y E. coli ATCC 25922 sobre lechuga batavia, encontrándose una mayor reducción de las poblaciones con concentraciones de $1,7 \%$.

\section{MATERIALES Y MÉTODOS}

Se utilizaron lechugas variedad batavia, de un mismo lote, provenientes de Productos Agrícolas Agua Clara (Mosquera-Cundinamarca), las cuales fueron cosechadas en la mañana y clasificadas por tamaño con un peso de $500 \mathrm{~g}$ aproximadamente, color visualmente uniforme y ausencia de daños fisiológicos y mecánicos, El material vegetal seleccionado fue sometido a tratamientos con ácidos orgánicos (láctico 1,7\%, cítrico 1,7\%, acético $1,7 \%$, y agua (grupo testigo) y posteriormente empacadas en bolsas perforadas para iniciar el seguimiento de las propiedades en cuarto frío. Los tratamientos se realizaron mediante microaspersión (sobre las hojas externas) e inmersión del tallo durante 30 segundos, sin lavado ni secado posterior. Luego del tratamiento se transportaron inmediatamente a los laboratorios de la Universidad de Bogotá Jorge Tadeo Lozano para realizar el seguimiento durante el viaje simulado, de acuerdo a la Tabla 1. En cada etapa del esquema del viaje simulado, se muestrearon 3 unidades (3 lechugas) de forma aleatoria dentro de cada tratamiento, se tomaron 20 gramos de cada una de las muestras, las cuales se congelaron con nitrógeno líquido y se conservaron a $-20^{\circ} \mathrm{C}$ para la extracción y determinación de compuestos fenólicos totales y actividad antioxidante. 
Tabla 1: Esquema de viaje simulado para el seguimiento de propiedades de lechugas tratadas con cada uno de los ácidos orgánicos (esquema a condiciones poscosecha en la Sabana de Bogotá-Colombia)

\begin{tabular}{|l|c|c|c|}
\hline \multicolumn{1}{|c|}{ Etapa del viaje simulado } & \multicolumn{3}{c|}{ Condición almacenamiento } \\
\cline { 2 - 4 } & $\begin{array}{c}\text { Temperatura } \\
\left({ }^{\circ} \mathrm{C}\right)\end{array}$ & $\begin{array}{c}\text { Tiempo de etapa } \\
(\mathrm{h}) / \text { tiempo total }(\mathrm{d})\end{array}$ & $\begin{array}{c}\text { Humedad } \\
\text { Relativa }(\%)\end{array}$ \\
\hline Recolección, selección y tratamiento (Etapa I) & 16 & $3 \mathrm{~h} / 0,1 \mathrm{~d}$ & 63 \\
\hline $\begin{array}{l}\text { Transporte del sitio de cosecha al centro de acopio (Etapa } \\
\text { II) }\end{array}$ & 16 & $3 / 0,2 \mathrm{~d}$ & 63 \\
\hline Tiempo en la comercializadora antes del viaje (Etapa III) & 10 & $24 / 1,3 \mathrm{~d}$ & 80 \\
\hline $\begin{array}{l}\text { Traslado al aeropuerto desde la comercializadora, tiempo de } \\
\text { espera y transporte aéreo/ terrestre hasta el puerto (Etapa } \\
\text { IV) }\end{array}$ & 3 & $24 / 2,3 \mathrm{~d}$ & 85 \\
\hline Viaje en barco hasta el destino (Etapa V) & 3 & $240 / 12,3 \mathrm{~d}$ & 85 \\
\hline Almacenamiento en anaquel (Etapa VI) & $4-6$ & $168 / 19,3 \mathrm{~d}$ & 85 \\
\hline
\end{tabular}

\section{Calidad física y pérdida de peso}

La calidad física se describe en función de los parámetros mínimos para su comercialización, cuantificada como el porcentaje de área superficial dañada o pardeada de la lechuga. Esta medida subjetiva se realizó de forma aleatoria y por triplicado. La calidad de la lechuga fue evaluada de forma individual sobre una escala de 1 a 5 de acuerdo al porcentaje de área superficial dañada. Donde 1 era inaceptable (superficie dañada o pardeada mayor al $50 \%$ ); 2 era mala (20-50\% de la superficie dañada o pardeada); 3 era aceptable (5-20\% de la superficie dañada o pardeada); 4 era buena (superficie afectada $<5 \%$ ); y 5 era excelente (sin daños). Los resultados fueron expresados como índice de calidad. Además se determinó el porcentaje de pérdida de peso con bloques de 6 unidades. Con el fin de evaluar el grado de pardeamiento enzimático y comparación entre tratamientos se determinó color sobre el corte trasversal del tallo de la lechuga, usando un colorímetro (Konica Minolta CR410, Ramsey, NJ, USA), en el sistema $\mathrm{CIEL}^{*} \mathrm{C}^{*} h^{*}$.

\section{Determinación de acidez titulable, sólidos solubles}

Las muestras de lechuga congelada se cortaron en trozos, se pesaron 25 gramos de cada una y se homogenizaron durante $1 \mathrm{~min}$ con $20 \mathrm{~mL}$ de agua destilada usando un homogenizador comercial (Osterizer superdeluxe). El homogenizado se llevó a ebullición durante $15 \mathrm{~min}$, con agitación constante y se determinaron sólidos solubles con un refractómetro. Posteriormente se completó el volumen a $250 \mathrm{~mL}$ con agua destilada, se filtró y se conservó el filtrado para la determinación de acidez titulable. Para la acidez titulable, se tomaron $50 \mathrm{~mL}$ del filtrado y se adicionaron $50 \mathrm{~mL}$ de agua destilada. Se tituló con $\mathrm{NaOH} 0,01 \mathrm{~N}$, utilizando fenoftaleína como indicador, hasta observar un cambio de color, el cual fue confirmado mediante un potenciómetro ( $\mathrm{pH}$ meter Mettler Toledo), hasta un pH de 8,1 (Arrazola-Paternina et al, 2013).

\section{Determinación de contenido de compuestos fenólicos y actividad antioxidante}

Se pesaron $5 \mathrm{~g}$ de lechuga congelada, se homogenizaron con $5 \mathrm{~mL}$ de metanol al 99,9\%(Ultra-turrax T25 Basic), con baño de refrigeración a $0^{\circ} \mathrm{C}, 2 \mathrm{~mL}$ del homogenizado se centrifugaron a 10000 r.p.m. durante 5 min. Se conservó el sobrenadante para la determinación de compuestos fenólicos y actividad antioxidante. Los compuestos fenólicos se determinaron por método espectrofotométrico, usando el reactivo de FolinCiocalteu (Muñoz-Bernal et al,, 2017). Los resultados fueron expresados en equivalentes de ácido gálico como $\mathrm{mg} / 100 \mathrm{~g}$ de lechuga fresca. La actividad antioxidante se determinó mediante la decoloración del catión radical ABTS (Re et al., 1999) y también por el método del DPPH (Kim et al., 2002). La actividad antioxidante total fue expresada como equivalentes de Trolox (TEAC) en $\mathrm{mg} / \mathrm{g}$ de lechuga fresca.

\section{Análisis Microbiológico}

Se tomaron 10 gramos de las hojas exteriores de la lechuga y se adicionaron en $90 \mathrm{~mL}$ de agua peptonada al $0,1 \%$. Se hicieron diluciones seriadas tomando $1 \mathrm{~mL}$ de esta y se realizó la siembra por duplicado. Se realizaron conteos sobre placa de microorganismos mesófilos aerobios (agar plate count) a una temperatura de $35^{\circ} \mathrm{C}$ a las $48 \mathrm{~h}$, coliformes (agar violet red bile) a una temperatura de $35^{\circ} \mathrm{C}$ a las $48 \mathrm{~h}$, y de hongos y levaduras (agar potato dextrose) a una temperatura de $30^{\circ} \mathrm{C}$ durante $96 \mathrm{~h}$ de cultivo. 


\section{Análisis estadístico}

El análisis de los datos se realizó mediante ANOVA y las medias fueron comparadas a través de la prueba de Duncan utilizando el software Statgraphics, a un nivel del 95\% de confianza $(p<0,05)$.

\section{RESULTADOS Y DISCUSIÓN}

Los resultados se presentan en cuatro secciones: (i) Calidad física y pérdida de peso; (ii) Acidez titulable y sólidos solubles; (iii) Determinación de contenido de compuestos fenólicos y actividad antioxidante y (iv) Análisis microbiológico.

\section{Calidad física y pérdida de peso}

En la Figura 1, se observa el comportamiento del índice de calidad física para los diferentes tratamientos. La disminución de la calidad de la lechuga fue influenciada por las diferentes etapas del viaje simulado y por el tratamiento utilizado $(p<0,05)$; la calidad disminuye de forma más rápida cuando las lechugas se mantuvieron a $6^{\circ} \mathrm{C}$ (etapa de almacenamiento en anaquel), comparada con las etapa a $3^{\circ} \mathrm{C}$. Las lechugas (hojas externas) sin tratamiento y tratadas con ácido cítrico, mantuvieron su índice de calidad sobre el nivel aceptable, sin presentar diferencia estadística $(p>0,05)$. Por otro lado, como se observa en la Figura 1 , las lechugas tratadas (hojas externas) con ácidos láctico y acético, después de los 6 días del viaje simulado, mostraban pérdida de calidad, esto se pudo deber a que estos ácidos a esa concentración, tienen un efecto negativo sobre los tejidos (rompimiento). Los resultados demuestran que tratamientos con ácidos láctico y acético a las concentraciones estudiadas no favorecen la calidad de la lechuga. Por otro lado se puede observar que en general a menores temperaturas de almacenamiento se logra una menor velocidad de deterioro físico. Este comportamiento es normal teniendo en cuenta que el tiempo y temperatura de almacenamiento afectan directamente la calidad de las lechugas (Kounkeu et al., 2017; Tsironi et al., 2017).

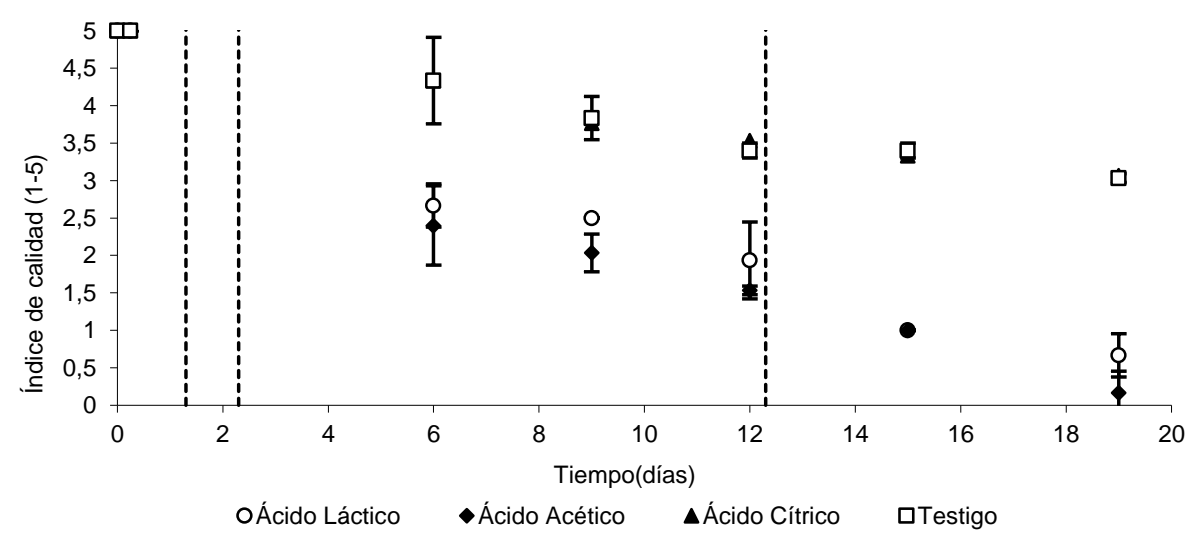

Fig. 1: Índice de calidad de lechuga variedad batavia en el esquema de viaje simulado

En la Figura 2, se encuentra el comportamiento de la pérdida de peso de los diferentes tratamientos durante el viaje simulado. Se puede observar que las muestras sin tratamiento presentaron la mayor pérdida de peso después del día 5 , con un valor de 15,5\%.

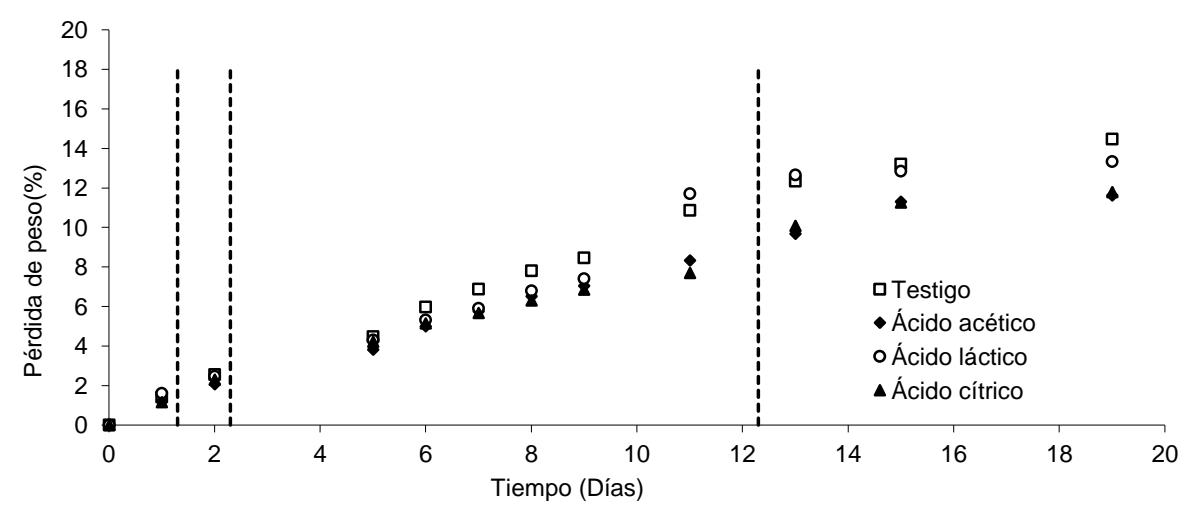

Fig. 2: Comportamiento del porcentaje de la pérdida de peso de lechugas control y tratadas con ácidos orgánicos: acético, láctico, cítrico y testigo en el tiempo. 
Los elevados valores de pérdida de peso se deben principalmente a la deshidratación de los tejidos, ya que el experimento se realizó sin ninguna película protectora que previniera este proceso. No obstante la aplicación de ácidos cítrico y acético disminuyó la pérdida de peso en un 3\% comparado con el grupo testigo. Sin embargo, no se evidenció diferencia estadística entre tratamientos $(p>0,05)$. En cuanto a las determinaciones de color en el tallo para evaluar el grado de pardeamiento enzimático, los datos obtenidos se encuentran en la Tabla 2. El color de la sección transversal del tallo fue influenciado de forma significativa por el tratamiento y las etapas del viaje simulado $(p<0,05)$. Antes del tratamiento las coordenadas fueron $\mathrm{L}=84,39 \pm 0,86, \mathrm{C}=10,56 \pm 0,66, \mathrm{H}=32110,56 \pm 5,44$.

Tabla 2: Valores de color de los tallos de las lechugas durante el tiempo del esquema del viaje simulado. Medida de color expresada en unidades de $L^{*}$ luminosidad, $C^{*}$ saturación, y $h^{*}$ ángulo de matiz

\begin{tabular}{|c|c|c|c|c|c|c|c|c|c|}
\hline \multirow{2}{*}{ Tratamiento } & \multicolumn{3}{|c|}{ Luego del tratamiento } & \multicolumn{3}{|c|}{ 15 días } & \multicolumn{3}{c|}{19 días } \\
\cline { 2 - 11 } & $\mathrm{L}$ & $\mathrm{C}$ & $\mathrm{h}$ & $\mathrm{L}$ & $\mathrm{C}$ & $\mathrm{h}$ & $\mathrm{L}$ & $\mathrm{C}$ & $\mathrm{h}$ \\
\hline \multirow{2}{*}{ Ácido Láctico } & 87,9 & 9,56 & 322 & 81,9 & 11,8 & 333 & 82,8 & 12,8 & 339 \\
& $\pm 0,9$ & $\pm 1,01$ & \pm 2 & $\pm 0,6$ & $\pm 0,8$ & \pm 4 & $\pm 0,9$ & $\pm 0,2$ & \pm 5 \\
\hline \multirow{2}{*}{ Ácido Acético } & 88,6 & 9,6 & 317 & 83,9 & 12 & 355 & 85,3 & 10,3 & 348,4 \\
& $\pm 0,8$ & $\pm 0,6$ & \pm 12 & $\pm 0,5$ & \pm 2 & \pm 2 & $\pm 0,4$ & $\pm 0,4$ & $\pm 0,6$ \\
\hline \multirow{2}{*}{ Ácido Cítrico } & 85,9 & 9,4 & 314 & 80,5 & 12,5 & 323,9 & 82,66 & 12,5 & 328,5 \\
& $\pm 0,3$ & $\pm 1,5$ & \pm 5 & $\pm 0,4$ & $\pm 0,2$ & $\pm 0,7$ & $\pm 0,09$ & $\pm 0,5$ & $\pm 0,6$ \\
\hline \multirow{2}{*}{ Testigo } & 83,4 & 10,7 & 320 & 82,9 & 14,5 & 333,2 & 83,19 & 14,10 & 328,1 \\
& $\pm 0,3$ & $\pm 0,2$ & \pm 6 & $\pm 0,6$ & $\pm 0,7$ & $\pm 0,2$ & $\pm 0,03$ & $\pm 0,13$ & $\pm 0,9$ \\
\hline
\end{tabular}

Luego de la aplicación del tratamiento, se encontraron mayores niveles de luminosidad en los materiales tratados con todos los ácidos. Con el paso del tiempo se observó un mayor nivel de pardeamiento enzimático (menor valor de $L^{*}$ ) en el grupo testigo en comparación con los tratamientos con ácidos, siendo el ácido acético el que logró una mayor inhibición del proceso. El valor del croma aumenta especialmente en el material testigo y los tratados con ácido láctico y ácido cítrico, indicando un color más intenso y oscuro. Al final del experimento, las lechugas que se pardearon a un mayor nivel fueron las tratadas con ácido cítrico y ácido láctico, sin diferencias significativas al final del experimento, mientras que los tallos de las lechugas que menos presentaron pardeamiento enzimático fueron los tratados con ácido acético, presentando un mejor comportamiento que el testigo. A pesar de que el ácido cítrico ha sido reportado como inhibidor de la enzima polifenoloxidasa (Dussán-Sarria et al., 2017) en este experimento a la dosis aplicada, no presentó buen comportamiento en la inhibición del pardeamiento enzimático, alcanzando menores valores de luminosidad cuando se compara con el testigo. Respecto a las etapas del viaje simulado, el pardeamiento enzimático se produce inclusive en las etapas de menor temperatura. En este contexto es importante resaltar la importancia de la aplicación de un tratamiento efectivo para prevenir el pardeamiento del tallo inmediatamente después del corte.

\section{Acidez titulable y sólidos solubles}

En la Figura 3 se observa el comportamiento de la acidez en la lechuga durante el viaje simulado. La tendencia de estos parámetros fue constante.

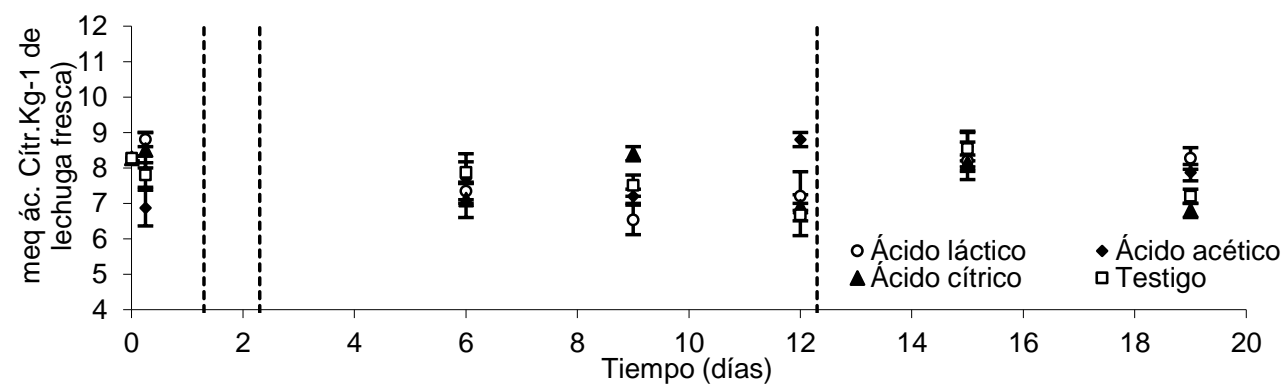

Fig. 3: Acidez titulable en lechuga variedad batavia con tratamiento (ácidos: láctico, acético y cítrico) y sin tratamiento en el esquema del viaje simulado (se presentan los puntos experimentales promedio, las barras de error representan la desviación estándar $n=3$ ). Las líneas punteadas separan las diferentes etapas.

En la Figura 4 se encuentran representados los datos del comportamiento de sólidos solubles, los cuales disminuyeron en promedio para todos los tratamientos $14 \%$, sin presentar diferencias estadísticas $(p>0,05)$. 
En este estudio, a pesar de que ocurrió incremento en el pardeamiento enzimático y pérdida de la calidad, los valores de acidez no se redujeron debido a la disminución en la velocidad de senescencia dada por la baja temperatura de almacenamiento durante 10 días, lo que ocasiona disminución en la tasa de respiración. Cuando las lechugas pasan a la temperatura de $10^{\circ} \mathrm{C}$, la tasa de respiración aumenta, ocasionando una mayor disminución de los sólidos solubles. En las Figuras 3 y 4, no se observa una tendencia definida que relacione la evolución de la acidez y sólidos solubles totales, con la pérdida de la calidad (Figura 1). Roura et al, (2000) reportaron que el consumo de ácidos y sólidos solubles está directamente relacionado con el proceso metabólico y no con daños en los tejidos. El aumento en la acidez en el día 12, probablemente surgió por la proliferación de bacterias productoras de ácidos (bacterias ácido lácticas), debido a la senescencia de las lechugas y reacciones biológicas de los tejidos.

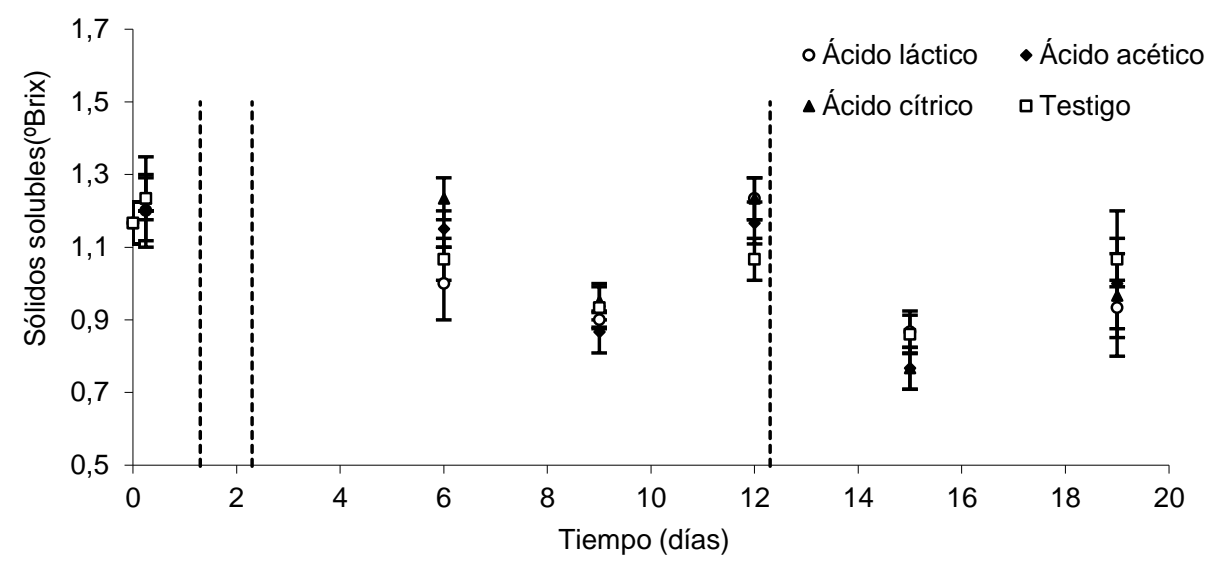

Fig. 4: Sólidos solubles totales en lechuga variedad batavia con tratamientos (ácidos: láctico, acético, cítrico) y sin tratamiento en el esquema del viaje simulado (se presentan los puntos experimentales promedio, las barras de error representan la desviación estándar $n=3$ ). Las líneas punteadas separan las diferentes etapas.

\section{Determinación de contenido de compuestos fenólicos y actividad antioxidante}

En la Figuras 5 y 6 se puede observar el comportamiento de la concentración de compuestos fenólicos y actividad antioxidante de la lechuga. Estos parámetros no presentaron diferencia estadística $(p>0,05)$ entre tratamientos y el grupo testigo.

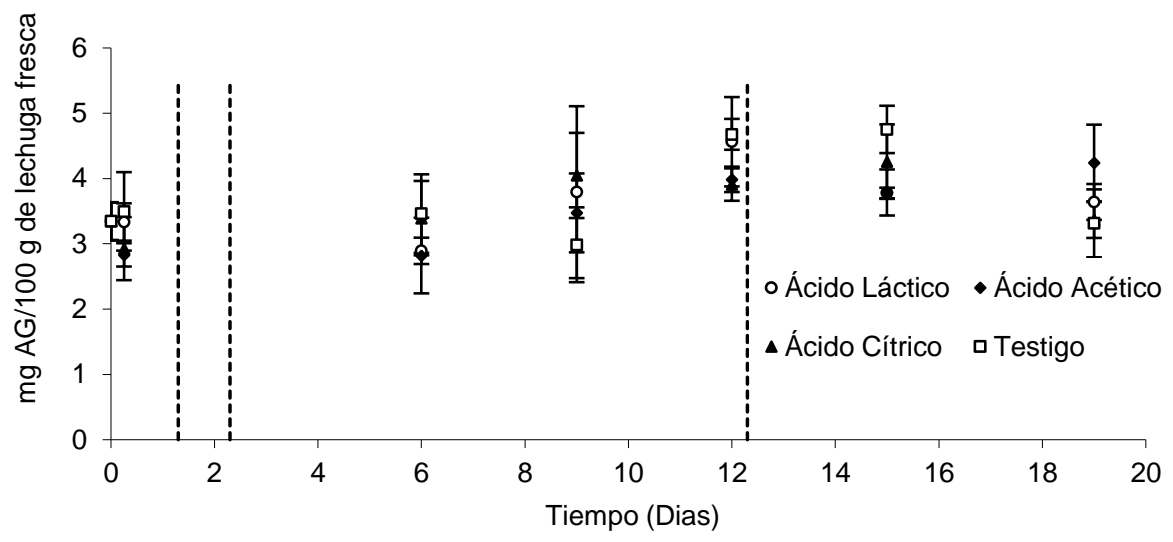

Fig. 5: Contenido total de compuestos fenólicos de la lechuga variedad batavia de los tratamientos estudiados (se presentan los puntos experimentales promedio, las barras de error representan la desviación estándar $n=3$ ). Las líneas punteadas separan las diferentes etapas.

Se puede observar en la Figura 5 un ligero aumento en la concentración de compuestos fenólicos durante el tiempo de refrigeración a $3^{\circ} \mathrm{C}$ mientras que luego de los 12 días los valores empezaron a disminuir levemente. Sin embargo al realizar la prueba de comparación de medias no se encontraron diferencias significativas entre los diferentes tratamientos. Este mismo comportamiento se observa en la Figura 6, con la actividad antioxidante. Altunkaya y Gökmen (2008) reportaron que las que condiciones óptimas de frío protegen la pérdida de compuestos fenólicos y por lo tanto en la actividad antioxidante, de forma similar a lo encontrado en este trabajo. En la investigación de Altunkaya y Gökmen (2008), el contenido de fenoles totales mostró una tendencia a la baja con el tiempo. El contenido de compuestos fenólicos disminuyó mucho más lentamente a $4{ }^{\circ} \mathrm{C}$ que a $25^{\circ} \mathrm{C}$, debido a que a bajas temperaturas se disminuye la velocidad de procesos metabólicos, como la respiración, la producción de etileno y la actividad de la enzima polifenoloxidasa. 
a

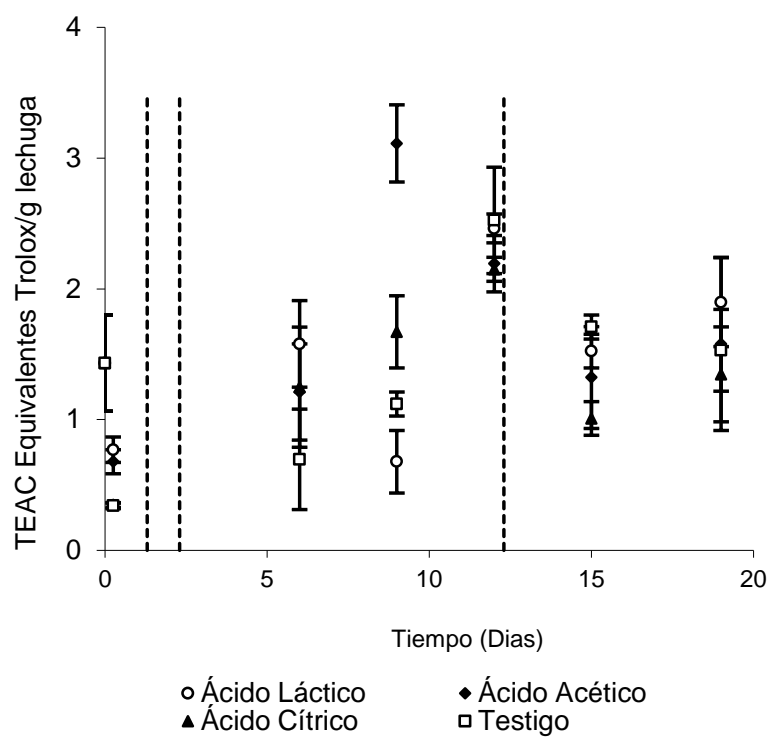

b

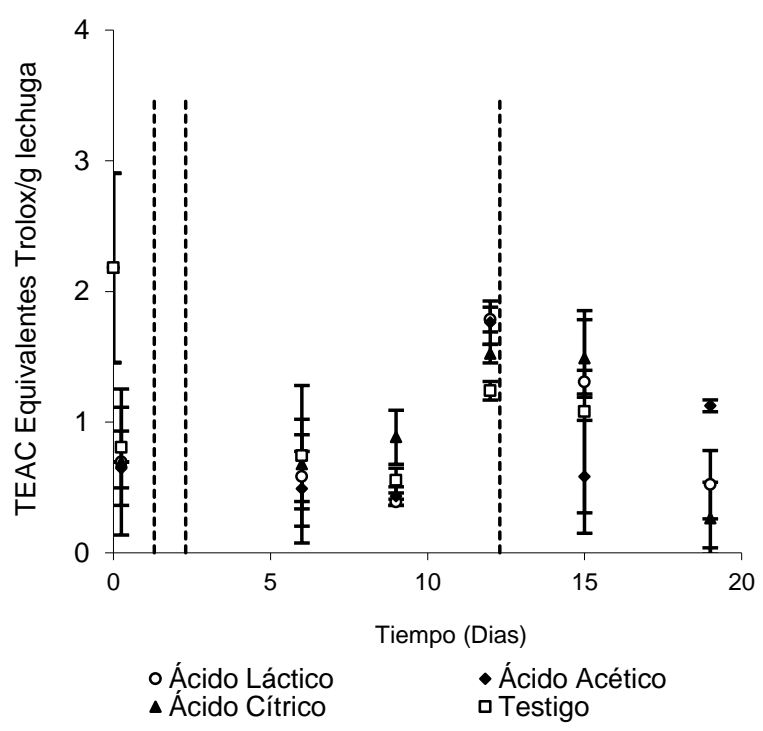

Fig. 6: Actividad antioxidante de los tratamientos estudiados: a) Método ABTS; b) Método DPPH (se presentan los puntos experimentales promedio, las barras de error representan la desviación estándar $n=3$ ). Las líneas punteadas separan las diferentes etapas.

\section{Análisis microbiológico}

En la Fig. 7 se reporta los datos de conteos de microorganismos mesófilos aerobios (Fig.7a), coliformes (Fig. 7b) y hongos y levaduras (Fig. 7c). En donde se observa una disminución de las poblaciones de microorganismos mesófilos aerobios, luego de 6 horas de aplicado el tratamiento, siendo el ácido láctico el que tuvo una mayor disminución de la población (1,2 unidades logarítmicas). Al contrario de esto se puede ver que las muestras sin tratamiento se mantuvieron constantes, por lo que los tratamientos influyeron de forma significativa sobre las poblaciones de mesófilos $(p<0,05)$. Las poblaciones de microorganismos mesófilos aerobios, fueron influenciadas por las condiciones de temperatura en la etapa de almacenamiento. Se observa, que cuando la temperatura estuvo a $3^{\circ} \mathrm{C}$, las poblaciones de microorganismos se mantuvieron estables, mientras que a $6^{\circ} \mathrm{C}$, se observó un leve aumento. Respecto a los coliformes, los tratamientos con ácido lograron disminuir de forma considerable las poblaciones luego de 6 horas. Todos los tratamientos reportaron aproximadamente una reducción de 1,3 unidades logarítmicas. Se puede observar en la Fig. 7b, un incremento considerable en las poblaciones microbianas en los tratamientos de ácido láctico y ácido acético, de 2,5 y 1,98 unidades logarítmicas respectivamente, asociados al deterioro de las lechugas tratadas con estos ácidos, como se puede ver en la Fig. 1.

a

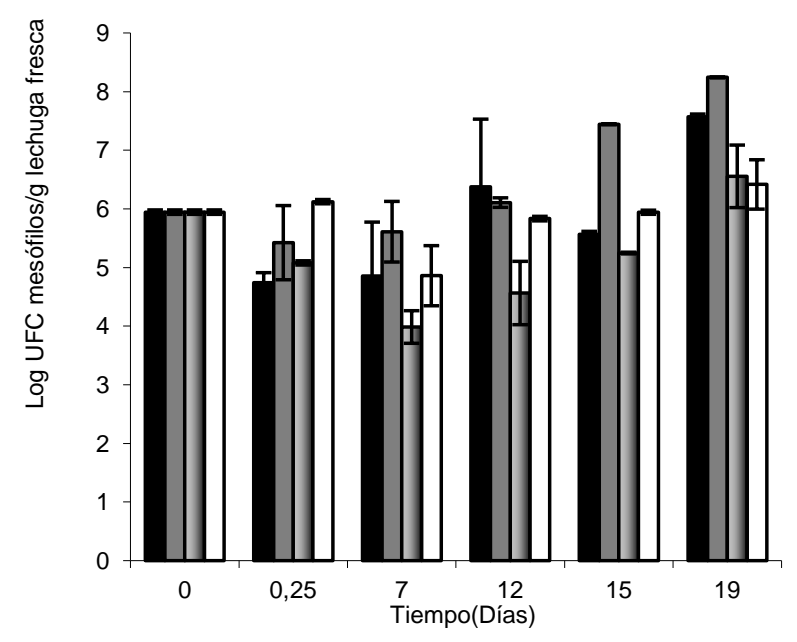

-Ácido Láctico घÁcido Acético घÁcido Cítrico aTestigo

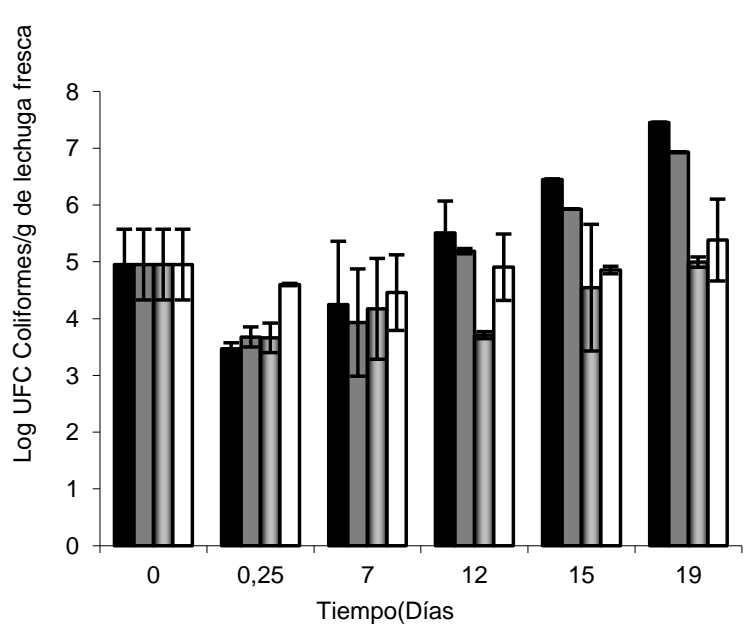

—Ácido Láctico םÁcido Acético םÁcido Cítrico םTestigo 
Fig. 7 (continuación)

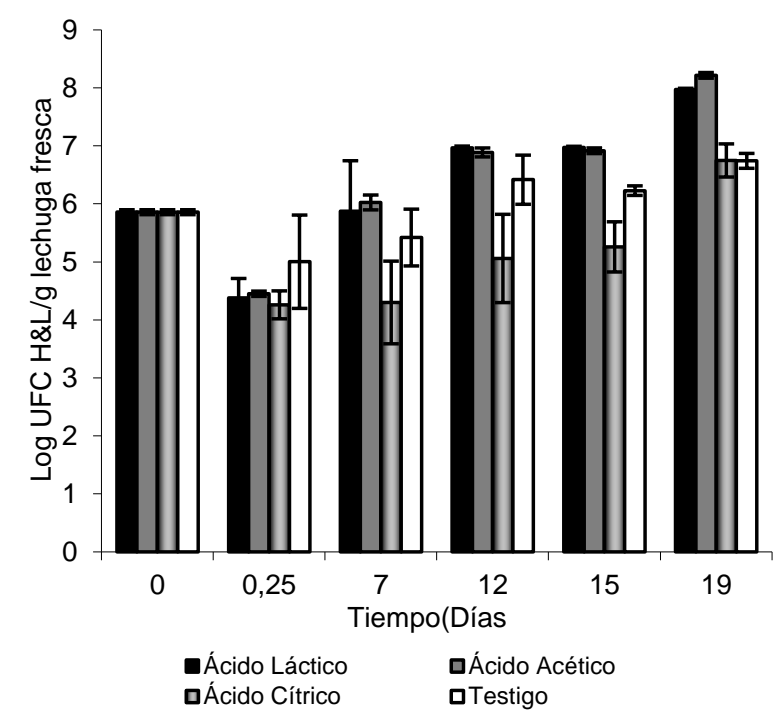

Fig. 7: Análisis microbiológico de los tratamientos estudiados: a) Población de mesófilos; b) Población de coliformes; c) Población de hongos y levaduras aerobios

Los conteos de hongos y levaduras, disminuyeron considerablemente al aplicar los tratamientos de ácidos cítrico, láctico y acético, siendo de 1,60, 1,48 y 1,41 unidades formadoras de colonias/gramo de lechuga respectivamente. De igual forma se puede observar como la temperatura influyó en el aumento considerable de poblaciones de hongos y levaduras sobre cada una de las lechugas (Figura 7c).

\section{CONCLUSIONES}

De acuerdo al estudio los sólidos solubles totales presentan una disminución durante el viaje simulado, debido a las diferentes temperaturas estudiadas. El ácido acético al 1,7\% tiene efecto positivo en la inhibición del pardeamiento enzimático de los tallos. La pérdida de peso, no presentó diferencias marcadas entre los tratamientos. Por otro lado, para mejorar la vida útil de la lechuga variedad batavia, es importante controlar la acción de microorganismos. Los tratamientos con ácidos orgánicos disminuyeron las poblaciones de mesófilos, coliformes, hongos y levaduras. Sin embargo el deterioro de las lechugas tratadas con ácido láctico y acético, ocasionó la mayor proliferación de microorganismos al final del ensayo. Se podría incrementar su vida útil con aplicación de películas con propiedades activas antioxidantes y antimicrobianas.

\section{AGRADECIMIENTOS}

Este trabajo se realizó bajo el proyecto "Aplicación de tecnologías para el manejo poscosecha de brócoli, espinaca y lechuga" financiado por el Ministerio de Agricultura y Desarrollo Rural y la Univ. de Bogotá Jorge Tadeo Lozano, en el grupo de investigación en Ingeniería de Procesos Químicos y Sistemas Industriales.

\section{REFERENCIAS}

Altunkaya, A. y V. Gökmen, Effect of Various Inhibitors on Enzymatic Browning, Antioxidant Activity and Total Phenol Content of Fresh Lettuce (Lactuca sativa), Food Chem., 107(3), 1173-1179 (2008)

Arrazola-Paternina, G., J. Barrera-Violeth y M. Villalba-Cadavid, Determinación Física y Bromatológica de la Guanábana Cimarrona (Annona glabra L.) del Departamento de Córdoba, Orinoquia, 17(2), 159-166 (2013)

Blanch, M., D. Alvarez y otros tres autores, Water Relations, Short-Chain Oligosaccharides and Rheological Properties in Lettuces Subjected to Limited Water Supply and Low Temperature Stress, Sci. Hortic., 225, 726-735 (2017)

Bohórquez, W., J. Gómez y V. Flórez, Factores Nutricionales y Alteración en el Contenido de Antocianinas Relacionados con el Ennegrecimiento de los Pétalos en Rosa (Rosa sp.), Rev. U.D.C.A Actualidad \& Divulgación Científica, 16(1), 103-112 (2013)

Castañeda-Ruales, G., C. Eslava-Campos y otros tres autores, Listeriosis en México: Importancia Clínica y Epidemiológica, Salud Públ. Méx., 56(6), 654-659 (2014)

Ding, T., F. Liu y otros cinco autores, Comparison of Different Cooling Methods for Extending Shelf life of Postharvest Broccoli, Int. J. Agric. \& Biol. Eng., 9(6), 178-185 (2016) 
Dussán-Sarria, S., A. Gaona-Acevedo y J. Hleap-Zapata, Efecto del Uso de Antioxidantes en Plátano Verde DominicoHartón (Musa AAB simmonds) Cortado en Rodajas, Inf. Tecnol., 28(4), 3-10 (2017)

Gutiérrez, D., G. Ruiz y otros dos autores, Uso de la Radiación UV-C en el Proceso de Elaboración de Hortalizas de IV Gama, Agrociencia Uruguay, 20(2), 7-13 (2016)

Kim, J.K., J.H. Noh y otros seis autores, The First Total Synthesis of 2,3,6-tribromo-4,5- dihydroxybenzyl methyl ether (TDB) and its Antioxidant Activity, Bull. Korean Chem. Soc., 23(5), 661-662 (2002)

Kounkeu, P.F., I. Khan y otros tres autores, Inactivation of Bacterial Pathogens on Lettuce, Sprouts, and Spinach Using Hurdle Technology, Innov. Food Sci. Emerg. Technol., 43, 68-76 (2017)

McKellar, R.C., D.I. LeBlanc y otros dos autores, Simulation of Escherichia coli O157:H7 Behavior in Fresh-Cut Lettuce under Dynamic Temperature Conditions During Distribution from Processing to Retail, Foodborne Pathog. Dis., 9(3), 239-244 (2012)

Muñoz-Bernal, O., G. Torres-Aguirre y otros cinco autores, Nuevo Acercamiento a la Interacción del Reactivo de FolinCiocalteu con Azúcares Durante la Cuantificación de Polifenoles Totales, Tip Revista Especializada en Ciencias Químico Biológicas, 20(2), 1-11 (2017)

Park, S.H., M.R. Choi y otros cinco autores, Use of Organic Acids to Inactivate Escherichia coli o157:h7, Salmonella typhimurium, and Listeria monocytogenes on Organic Fresh Apples and Lettuce, J. Food Sci., 76(6), $293-298$ (2011)

Re, R., N. Pellegrini y otros cuatro autores, Antioxidant Activity Applying an Improved ABTS Radical Cation Decolorization Assay, Free Radical Biol. Med., 26(9 y 10), 1231-1237 (1999)

Rivera, A., P. Restrepo y C. Narváez, Polifenoloxidasa y Peroxidasa de Pulpa de Uva Caimarona (Pourouma cecropiifolia), Rev. Colomb. Quim., 33(1), 57-66 (2004)

Roura, S.I., L.A. Davidovivhy y C. del Valle, Posthavest Changes in Fresh Swiss Chard (Beta vulgaris, type cycla) under Different Storage Conditions, J. of Food Quality, 23(2), 137-147 (2000)

Tsironi, T.E. Dermesonlouoglou y otros cuatro autores, Shelf-life Prediction Models for Ready-to-Eat Fresh Cut Salads: Testing in Real Cold Chain, Int. J. Food Microbiol., 240, 131-140 (2017)

Tirpanalan, Ö, M., Zunabovic y otros dos autores, Mini review: Antimicrobial Strategies in the Production of Fresh-Cut Lettuce Products, Science Against Microbial Pathogens: Communicating Current Research and Technological Advances, 1ra edición, 176-188, Formatex, Vienna, Austria (2011) 
